\title{
Lugares de religião de matriz africana no território de Guarulhos
}

\author{
Cláudia Regina Plens*
}

PLENS, C.R. Lugares de religião de matriz africana no território de Guarulhos.

R. Museu Arq. Etn., 26: 151-162, 2016.

Resumo: Embora pouco conhecidas, dados apontam para a importância de religiões de matriz africana no município de Guarulhos, em comparação com os demais municípios do Estado de São Paulo. Este artigo inicia uma discussão acerca desta importância a partir de uma primeira leitura da representatividade de terreiros religiosos no município, propondo uma investigação mais aprofundada da questão para compreensão histórica e cultural que, amarradas nas questões religiosas, permitam o melhor conhecimento da sociedade e na ampliação de pesquisas e políticas de preservação para esse cenário.

Palavras-Chave: Religião de matriz africana; Arqueologia dos Lugares sagrados; intolerância religiosa.

"Que diabo iria o menino fazer pela vida afora com todas essas religiões, não ia ter tempo para nada, a correr de igreja para igreja. Bastava com o católico e o candomblé que, como todos sabem, se misturam e se entendem... Batizava no padre, amarrava o santo no terreiro.

\section{Introdução}

As religiões de matriz africana se destacam de tempos em tempos no imaginário da população brasileira de maneira diluída, por meio de novelas e literatura, mas sua real importância entre seus praticantes e o que elas representam do ponto de vista histórico-cultural ainda é desconhecido.

No Brasil são variadas essas expressões religiosas, batuque, tambor de mina, umbanda - "bricolage europeia-africana-indígena, símbolo das próprias origens brasileiras" (Prandi, 1996: 73) -, e o candomblé, todos com variedades em

${ }^{*}$ ) Arqueóloga, Professora do Departamento de História da UNIFESP. seus cultos, ora pela procedência africana, ora pela especificidade histórica e geográfica em que se desenvolveu a prática em nosso solo (Hubert, 2011: 83).

Na atualidade, no estado de São Paulo, tornam-se notórias a devoção e práticas religiosas de matriz africana, principalmente no dia 08 de dezembro, durante a celebração da Nossa Senhora da Conceição, quando o litoral se enche de adeptos para o culto de Iemanjá (Amaral e Silva, 2006: 115). No entanto, no dia a dia, desconhecemos os lugares sagrados e os praticantes dessas religiões, fazendo com que as políticas públicas acerca da preservação do conhecimento e dos lugares de importância para essas religiões não possam atuar sobre seus legados culturais. 
Durante a execução do projeto Pesquisa e Inventário do Patrimônio Arqueológico de Guarulhos - PIPAG - que teve por objetivo compreender os lugares de importância cultural para o desenvolvimento histórico do município de Guarulhos, foi notada a importância dos rituais associados à religião de matriz africana em vários espaços da cidade. Mais do que isso, a própria relação da universidade com seus alunos, bem como agentes da prefeitura municipal, permitiu captar esta importância no contexto guarulhense.

Ainda que de maneira inicial, essa pesquisa revela a necessidade de se compreender esse tema raramente abordado do ponto de vista histórico e científico e que certamente é valiosa para a compreensão das relações sociais que se forjam dentro do contexto do território estudado.

Dentro do mapeamento feito pelo PIPAG, buscamos compreender a diversidade cultural do município, por meio da investigação da Arqueologia da Paisagem, para iniciar uma tecelagem geográfica e temporal dos lugares de importância social, destacando-se o estudo inicial dos lugares de culto das religiões de matriz africana na atualidade.

Em contextos de colonização, onde duas ou mais sociedades se relacionam atuando com diferentes formas de poder, há distintas formas de contatos, podendo haver resistência ou não. Do ponto de vista da arqueologia, o estudo de práticas de resistências no contexto diário é bastante difícil por meio da cultura material cotidiana, sendo sua forma mais expressiva e de melhor acesso por meio do estudo de práticas religiosas (Orser e Funari, 2001: 63).

\section{Problemas históricos, estatísticos e patrimoniais}

Mesmo que marginalizados, excluídos de suas culturas e instituições sociais, a partir da diáspora africana, religiões e a diversidade de cultos passaram a ser praticadas em novas terras, longe do continente africano. Porém, não de forma livre. A maioria das religiões e outras formas de expressão foram duramente perseguidas e suas práticas proibidas durante boa parte da história do Brasil depois da descoberta pelos europeus.
O candomblé, por exemplo, foi perseguido pelo governo e, também, por órgãos da imprensa que se pronunciavam contra essa prática religiosa. O governo, por meio da força policial, perseguiu seus praticantes, invadiu e depredou terreiros, e seus objetos foram profanados, apreendidos e destruídos (Prandi, 2009: 51).

A prática do candomblé manteve-se por meio de diferentes formas de resistência, às vezes camuflando a prática em meio à mata ou a mascarando, por meio do sincretismo com o catolicismo, que substituía os orixás por santos e adotava o calendário de festas da igreja católica (Prandi, 2004: 225).

De acordo com o Censo IBGE, no ano de 2000, 0,3\% dos brasileiros se declararam seguidores de religiões afro-brasileiras. Contudo, embora a atual liberdade de expressão religiosa garantida pela Constituição Federal de 1988, sabe-se que muitos dos praticantes do candomblé ainda se declaram católicos, sendo os números do Censo muito aquém dos números verdadeiros (Prandi, 2004: 224-5).

O mesmo problema estatístico parece ocorrer entre os praticantes da umbanda. De acordo com Prandi (2004: 226), pelo histórico do desenvolvimento da religião ter sido paralelo aos preceitos do espiritismo, muitos praticantes ainda se autodeclaram espíritas, configurando em mais problemas para se determinar o número de praticantes da religião.

Atualmente, com a liberdade religiosa garantida constitucionalmente, não há mais a prática de repressão que coíba os cultos por força policial. $O$ que não quer dizer que seus praticantes possam celebrar suas cerimônias livremente, pois segmentos sociais específicos, sobretudo ligados a religiões neopentecostais, os vêm hostilizando e profanando seus espaços (Prandi, 2004; Santos, 2014).

Do ponto de vista patrimonial, o não ou o pouco reconhecimento de lugares religiosos como bem cultural da nação, em comparação com os espaços da igreja católica tombados e preservados pelos órgãos governamentais, faz com que o governo corrobore com a marginalização das religiões de matriz africana, colocando-as em uma categoria inferior à da religião católica. 
No Brasil, o primeiro tombamento de terreiro aconteceu na Bahia na década de 1980, com o Ilê Axé Iyá Nassô Oká (Terreiro da Casa Branca), o qual se acredita ter sido o primeiro terreiro de candomblé da Bahia. Esse caso, como bem coloca Santos (2014), foi uma ruptura no paradigma patrimonial que, até então, reconhecia aspectos da cultura luso-brasileira como passiveis de preservação por seu valor cultural, em detrimento de outros aspectos culturais. Velho (2006) relata que à época da discussão sobre a pertinência desse primeiro tombamento, período em que a cultura imaterial ainda não era tratada como tal, era alegado que religião não era algo passível de tombamento, muito embora inúmeras igrejas católicas já tivessem sido tombadas.

O estado da Bahia despontou na originalidade do tombamento, no reconhecimento do valor cultural de uma religião de matriz africana. Contudo, embora a prerrogativa do tombamento de um terreiro na década de 1980, até os dias atuais, todo o estado, com seus 1162 terreiros mapeados, tem o tombamento de apenas 8 terreiros, sendo 7 em Salvador e 1 no município de Cachoeira. Mais do que isso, apenas terreiros de candomblé estão sendo reconhecidos do ponto de vista patrimonial em prejuízo às demais religiões de matriz africana (Santos, 2014).

O tombamento previsto pelo Decreto-lei $\mathrm{n}$. 25/37 não tem como objetivo preservar a totalidade de bens culturais, mas aqueles que sejam representativos da identidade e da memória social. Nesse sentido, é essencial que haja políticas que estabeleçam os critérios claros que atendam esta finalidade de modo democrático e que todos possam se sentir representados (Silva, 2006).

\section{Cultos, memória e sociedade}

No Brasil é comum nas esquinas das cidades se deparar com oferendas. Mas em Guarulhos o número de oferendas é elevado, e são localizadas ainda em maior quantidade na área norte do município, dentro da mata, próximo às fontes d'água e pelos caminhos e trilhas. Os mesmos caminhos que levam às ruínas de mineração de ouro do século XVI do município (ver: Plens e Porto). Nas proximidades da ruína de mineração do Tanque Grande há, inclusive, uma cachoeira identificada como "Cachoeira da Macumba".

Dentro desse contexto social da cultura negra, o reconhecimento da importância das expressões religiosas de matriz africana em Guarulhos, destaca-se um patrimônio, uma casa que é tida pela cultura local de valor ligado à cultura negra. A propriedade conhecida como Casa da Candinha, sede da antiga Fazenda Bananal, está localizada atualmente no bairro de Santos Dumont, município de Guarulhos, próximo ao Aeroporto Internacional de Guarulhos.

Trata-se de uma casa rural oitocentista tombada pelo município por ser considerada uma das únicas remanescentes do período colonial da Região Metropolitana de São Paulo (Decreto n. 21.143/2000). O sítio, de propriedade da Prefeitura Municipal de Guarulhos, situado na Serra da Cantareira, é uma Unidade de Conservação de Proteção Integral (Lei Municipal n. 6.475/2008) com o nome de Parque Natural Municipal da Cultura Negra Sítio da Candinha, com uma área de $177 \mathrm{mil} \mathrm{m}^{2}$, cujo objetivo é a preservação do patrimônio histórico, arquitetônico e cultural, e a conservação da biodiversidade.

Localizado em meio a uma área ainda bastante arborizada, o parque insere-se no contexto do corredor ecológico Cantareira-Mantiqueira, fazendo limites com os Parques Estaduais da Cantareira e de Itaberaba, além de sua proximidade com a Área de Proteção de Mananciais do Tanque Grande.

A ressignificação dos valores culturais da Casa da Candinha pela população local é forte e expressiva, sendo que lhe são conferidos valores ligados aos movimentos negros. Tal processo resultaria da transmissão oral de que a D. Candinha - que foi proprietária do imóvel já na primeira metade do século XX - demonstrara ter sido uma mulher muito generosa, acolhedora e festiva com toda a população, inclusive com os descendentes africanos da fazenda. A presença dessa "memória africana" e escrava na Casa é tão forte que a população local acredita que o porão da Casa teria sido uma senzala do tempo da escravidão, embora não haja, ainda, comprovação desse uso do espaço. 
De acordo com Prandi, (1991) o município ainda teria o primeiro terreiro de candomblé de São Paulo. Este terreiro, o Ilê Orinxalá Fun Fun, foi diretamente derivado do Terreiro Casa Branca do Engenho Velho e Gantois:

Tendo ido iniciar-se no candomblé diretamente no terreiro de Gantois de Mãe Menininha nos anos de 1950, o paulista Babá Idérito [do Nascimento Corral] após estudar iorubá na USP, em 1997, e empreender várias viagens à África, dirige hoje o terreiro de candomblé talvez mais africanizado do país. No barracão de sua roça em Guarulhos, lê-se, afixado na parede, o seguinte: "Todas as modificações que foram, e que continuarão a ser introduzidas nesta casa, servirão para conduzi-la até suas origens, a África."

O Babá Idérito faleceu em 1991 e o terreno e casa foram herdadas pela sua família; contudo, o babalorixá Carlos Camargo, de Oxum, manteve a casa até recentemente, quando da ordem de despejo e da demolição da casa. Houve um pedido de tombamento do terreno que foi avaliado e denegado pelo Conselho do Patrimônio Histórico, Artístico, Ambiental e Cultural do Município de Guarulhos.

Ademais, o município conta atualmente com um esforço conjunto pela liberdade de suas expressões religiosas por meio da articulação realizada pelo Conselho das Religiões Candomblé e Umbanda de Guarulhos, composto por oito entidades, ATUCAG (Associação dos Templos de Umbanda e Candomblé de Guarulhos), INTECAB/SP, FENUG, FERO (Federação Espiritualista Reino dos Orixás), FETUCAM (Federação das Tendas de Umbanda e Candomblé de Guarulhos), MOVIASÉS (Movimento de União e Luta dos Asés), NAFRO/PM (PMs do Axé), UARAB (União dos Adeptos das Religiões Afro-brasileiras) e UMUG.

\section{Um lugar no espaço e no tempo}

De acordo com Prandi (2006), terreiros são os lugares considerados templos das religiões de matriz africana. Primeiramente, os terreiros eram os quintais de casas, lugares a céu aberto, e, posteriormente, muitos lugares de culto ganharam casas para salvaguardar seus objetos cerimoniais. A todo o conjunto, terreno e casa, se considera o terreiro destas religiões, ou ilê axé, como são denominados. Um terreiro sem a casa ainda é reconhecido como terreiro, uma vez que os cultos, originalmente, ocorriam a céu aberto.

Dentro da perspectiva da Arqueologia da Paisagem, destacam-se os estudos de lugares como pontos de conexão entre ambiente, pessoas e significados responsáveis pelo processo de criação do comportamento humano, onde os indivíduos desenvolvem a cognição e a percepção acerca do espaço - e os comportamentos humanos intrínsecos a ele -, e o utiliza como marco para a promoção e transmissão de conhecimento e memória social.

A materialidade da relação entre lugar, pessoas e memória que se desdobra sobre aspectos sociais, políticos, econômicos e simbólicos da paisagem é o cerne da pesquisa arqueológica (Forbes, 2007; Bradley, 2000; Bowser e Zedeño, 2009). Ao mesmo tempo em que a paisagem pode definir alguns padrões comportamentais, as modificações no comportamento social são refletidas na cultura material e no uso do espaço (Zedeño e Browser, 2009: 1-8).

Assim como os artefatos, as paisagens, os lugares e os caminhos também têm seus ciclos de vida; eles são utilizados, marcados, modificados, reutilizados e, por fim, abandonados.

A existência do lugar depende das inúmeras interações entre pessoas e espaços com diferentes histórias de vida que o modificam constantemente, conferindo diferentes ressignificados na memória social (Zedeño e Browser, 2009: 8-9).

Por essa razão, os lugares não podem ser considerados como unidades monolíticas, quando para a compreensão do comportamento humano, mas considerados no exercício de suas múltiplas funções. Mais do que isso, os lugares não são isolados, mas interconectados com outros lugares que ajudam a conferir o seu significado (Zedeño e Browser, 2009: 8-9).

Uma maneira de se acessar as múltiplas camadas de histórias e relações sociais é partin- 
do de estudos biográficos de lugares e histórias locais que expliquem causas e consequências de mudanças ocorridas em cada lugar e em seus usuários. Progressivamente, essas múltiplas histórias ganham características de uma rede interconectada de lugares e relações sociais que, aos poucos, configuram a paisagem e o comportamento humano em tradições de longa duração: com variações local, regional e interculturais (Snead, 2009; Zedeño e Browser, 2009: 10; Erickson, 2009: 205).

A interconexão dos lugares ocorre a partir de caminhos e percursos dos mais diversos que engendram redes de contatos, de conhecimentos e de memória social (Snead et al., 2009: 01). Os caminhos conectam pessoas a outras pessoas, aos recursos e aos lugares sagrados, ligando as práticas cotidianas à visão cosmológica de uma sociedade. Quanto maior for a repetição dos movimentos das pessoas - conectando as estruturas por meio dos caminhos, interligando o mundano ao sagrado -, maior o estreitamento das relações sociais (Erickson, 2009: 206-7).

A religião, parte inerente da vida cotidiana, está representada em lugares específicos, mas ganham significados por suas redes de contatos e adjacências. Como salienta Hubert (1994: 15), pode ser difícil compreender que para outros grupos o sagrado pode se encontrar em uma pedra ou por toda uma montanha. Ao mesmo tempo, os sítios arqueológicos sagrados não podem ser localizados pontualmente em um mapa, ele deve se distinguir pelas suas adjacências.

Os lugares singulares compõem amplas paisagens que envolvem movimentos do mundo real e imaginário (Earle, 2009: 253). É, portanto, na ligação dos lugares do cotidiano com os sagrados que a rede de movimentos se formaliza, transformando os ressignificados culturais em materialidade, com sua carga de valores culturais, sociais e históricos.

\section{Território e Identidade}

Embora desde o início do projeto PIPAG tenhamos tentado enfocar a questão da religiosidade de matriz africana, encontramos dificuldades na obtenção de acesso às informações.
Muitos praticantes, assim como pais e mães de santo, não viam com "bons olhos" a questão do mapeamento dos terreiros.

De forma que para nosso estudo, primeiramente partimos de dados de acesso público disponíveis na internet da Federação de Umbanda e Candomblé do Estado de São Paulo (FUCESP), fundada em 1953. A partir dos dados levantados a partir do site da FUCESP tivemos acesso a todos os nomes e endereços de seus filiados.

Dado o histórico de perseguição e violência sofridas pelos praticantes das religiões de matriz africana, é evidente que a relação de filiados da FUCESP não deva representar nem a totalidade, nem a maioria dos terreiros existentes. Portanto, esses dados são apresentados como uma amostra representativa para uma primeira abordagem estatística dos terreiros.

Dentro do estado de São Paulo, destacam-se dois municípios pela alta quantidade de terreiros filiados a FUCESP: o primeiro é o município de São Paulo, com 30,7\% e, em segundo lugar, o município de Guarulhos, com $24,1 \%$. Contudo, o número populacional das duas cidades é distinto. Em 2010, o município de São Paulo registrou o número da população em 11,25 milhões e, em Guarulhos de 1,222 milhão (IBGE).

A partir de uma leitura da representatividade dos terreiros per capita, notamos que em Guarulhos há mais terreiros filiados a FUCESP do que São Paulo, levando Guarulhos a representar o município com mais terreiros per capita no estado de São Paulo.

A localização e dispersão dos terreiros registrados na FUCESP aponta a concentração de dois clusters, a leste e a oeste do município, sendo ambas as áreas dos primeiros e mais antigos núcleos de colonização de Guarulhos.

Para tentar compreender a representatividade da amostra dos terreiros filiados ao FUCESP, partimos para uma segunda metodologia de trabalho. A partir do curso de Arqueologia Histórica ministrado no Departamento de História da UNIFESP, dois alunos ${ }^{1}$ colaboraram com o projeto, elaborando como

1 Ubirajara Scuri e Luanda Lima 
trabalho final uma enquete entre os alunos da Escola Estadual Prof. Helio Polesel, na Vila Nova Bonsucesso, para o mapeamento de terreiros no Bairro do Bonsucesso, uma das áreas de concentração de terreiros filiados à FUCESP.
O objetivo da enquete foi saber se as crianças da população conheciam terreiros de umbanda e candomblé em suas vizinhanças e construir um segundo mapa focado em uma região menor e, desse modo, refinar a estatística de representatividade da amostra.

\begin{tabular}{lc|c}
\hline \multicolumn{1}{c}{ Município } & Número de terreiros & $\%$ \\
São Paulo & 28 & 30,76923 \\
Guarulhos & 22 & 24,17582 \\
Campinas & 4 & 4,395604 \\
São José dos Campos & 3 & 3,296703 \\
Santo André & 3 & 3,296703 \\
São Bernardo do Campo & 3 & 3,296703 \\
São Caetano do Sul & 2 & 2,197802 \\
Araçoiaba da Serra & 2 & 2,197802 \\
Cotia & 2 & 2,197802 \\
Fernandópolis & 2 & 2,197802 \\
Jundiaí & 2 & 2,197802 \\
Atibaia & 1 & 1,098901 \\
Barueri & 1 & 1,098901 \\
Borborema & 1 & 1,098901 \\
Bragança Paulista & 1 & 1,098901 \\
Caraguatatuba & 1 & 1,098901 \\
Descalvado & 1 & 1,098901 \\
Garça & 1 & 1,098901 \\
Guararema & 1 & 1,098901 \\
Ilha Comprida & 1 & 1,098901 \\
Leme & 1 & 1,098901 \\
Marília & 1 & 1,098901 \\
Mauá & 1 & 1,098901 \\
Mogi das Cruzes & 1 & 1,098901 \\
Monte Alegre do Sul & 1,098901 \\
Ribeirão Pires & 1 & 1,09890901 \\
Rio Grande da Serra & 1,098901 \\
\hline Salto de Pirapora & 1 & \\
Sumaré & 1 & \\
\hline & 1 & \\
\hline
\end{tabular}

Tabela 1: Relação de terreiros de umbanda e candomblé filiados ao FUCESP 
Terreiros de Guarulhos Registrados

\begin{tabular}{|c|c|c|}
\hline Denominação & Endereço & Bairro \\
\hline $\begin{array}{l}\text { Templo de Umbanda Mamãe Oxum e } \\
\text { Pai Xangô }\end{array}$ & $?$ & $?$ \\
\hline $\begin{array}{l}\text { Templo de Umbanda Nanã Buroque - } \\
\text { Obaluaê }\end{array}$ & $\begin{array}{l}\text { Rua Marco Antonio Liotta, } \\
30\end{array}$ & $\begin{array}{r}\text { Jardim Rosa de } \\
\text { França }\end{array}$ \\
\hline Templo de Umbanda União e Amor & Av. Guarulhos, 3118 & Ponte Grande \\
\hline $\begin{array}{l}\text { Templo Espírita de Umbanda Senhora } \\
\text { da Guia e Pai Ogum Negê }\end{array}$ & Rua Tailândia, 114 & Santa Cecília \\
\hline $\begin{array}{l}\text { Tenda de Umbanda Caboclo Flecha } \\
\text { Dourada e Pai Benedito do Cruzeiro }\end{array}$ & Rua Lebori Reges, 163 & Jardim Domingos \\
\hline $\begin{array}{l}\text { Tenda de Umbanda Caboclo Pena Verde } \\
\text { e Pai João da Mata }\end{array}$ & Rua Piauí, 174 , casa 2 & $\begin{array}{r}\text { Jardim Santa Tere- } \\
\text { zinha }\end{array}$ \\
\hline $\begin{array}{l}\text { Tenda de Umbanda Caboclo Pena Verde } \\
\text { e Preto Velho Africano }\end{array}$ & Rua Planaltino, 260 & $\begin{array}{r}\text { Jardim Presidente } \\
\text { Dutra }\end{array}$ \\
\hline $\begin{array}{l}\text { Tenda de Umbanda Caboclo Sete Mon- } \\
\text { tanhas } 55\end{array}$ & Rua Mario Lago, 96 & Jardim Munira \\
\hline $\begin{array}{l}\text { Tenda de Umbanda Caboclo Tupã e Pai } \\
\text { Bernardo }\end{array}$ & Rua 9, 119 & Jardim das Olivas \\
\hline $\begin{array}{l}\text { Tenda de Umbanda Cacique Ubirajara e } \\
\text { Vó Benedita e Ilê sé Opó Orisa Fun Fun }\end{array}$ & Rua Brás Cubas, 59, apto. 01 & Parque Renato Maia \\
\hline $\begin{array}{l}\text { Tenda de Umbanda Chico Boiadeiro e } \\
\text { Mamãe Oxum }\end{array}$ & Rua Paulo Mendes, 294 & \\
\hline Tenda de Umbanda Mãe Iemanjá & Rua Alhandra, 238 & Cidade Serôdio \\
\hline Tenda de Umbanda Pai Be & Rua Bela Vista, 631 & Centro \\
\hline $\begin{array}{l}\text { Tenda de Umbanda Vovô Sebastião e } \\
\text { Caboclo Rompe Mato }\end{array}$ & $\begin{array}{l}\text { Rua Amália Golin Pagnocelli, } \\
660\end{array}$ & Jd. Fortaleza \\
\hline $\begin{array}{l}\text { Cantinho das Orações Caminho de } \\
\text { Aruanda, Caboclo Lírio Verde e Vovó } \\
\text { Maria Conga }\end{array}$ & Rua das Palmeiras, 478 & Vila Augusta \\
\hline Casa de Caridade Caboclo 7 Luas & Rua Arakci Borazanian, 182 & $\begin{array}{r}\text { Parque Continental } \\
\text { II }\end{array}$ \\
\hline Casa de Caridade Raízes de Aruanda & Rua Antônio Cristovam, 66 & Jardim Bom Clima \\
\hline $\begin{array}{l}\text { Casa de Caridade Umbandistas Estrela } \\
\text { do Amanhecer }\end{array}$ & Rua Vasco Brancaleone, 42 & Parque Marabá \\
\hline $\begin{array}{l}\text { Casa de Oração Erê Mariana e Baiana } \\
\text { Serafina }\end{array}$ & Rua Jardel Filho, no 459 & $\begin{array}{r}\text { Residencial Parque } \\
\text { Cumbica }\end{array}$ \\
\hline $\begin{array}{l}\text { Templo de Umbanda Caboclo Águia } \\
\text { Dourada e Pai Joaquim de Angola }\end{array}$ & $\begin{array}{l}\text { Rua Joaquim Miranda, } 21 \text { - } \\
\text { sala } 2\end{array}$ & Vila Augusta \\
\hline $\begin{array}{l}\text { Templo de Umbanda Cacique Flecha } \\
\text { Dourada }\end{array}$ & Alameda Yaya, 79 & Gopoúva \\
\hline
\end{tabular}

Tabela 2: Relação dos terreiros do município de Guarulhos filiados ao FUCESP. 
Além disso, os alunos realizaram uma entrevista com pais de santo para entender o papel do candomblé para a comunidade e os problemas ainda enfrentados para a prática da religião.

O resultado da enquete revelou que as crianças, dentro de seus repertórios culturais, identificaram oito terreiros em $1,39 \mathrm{~km}^{2}$. Esse dado mostra que a densidade e a concentração de terreiros devam ser elevadas também entre os demais bairros do município (fig. 1).

Vale mencionar que no caso do terreiro Ilê Orisanlá Fun Fun, durante uma diligência do Conselho do Patrimônio Histórico, Artístico, Ambiental e Cultural do Município de Guarulhos, ao indagarmos a população local sobre localização da Rua Jutaí, endereço do terreiro, ninguém sabia informar. Contudo, ao perguntarmos pelo terreiro, a maioria das pessoas sabia apontar a direção do lugar, indicando mais uma vez como os terreiros estão arraigados na cultura local.
Por fim, dado que os cultos religiosos exigem uma parafernália complexa, decidimos traçar o mercado local para fornecimento destes materiais através da localização de lojas com artigos para os cultos em candomblé e umbanda, cuja localização também fosse de acesso público pela internet. $\mathrm{O}$ resultado foram seis grandes lojas com artigos para cultos de umbanda e candomblé no centro e outros bairros periféricos.

A entrevista com a Mãe Clarice de Oya e o Pai Vadinho de Ogun do Ilê Axé Ómòórisá Ógun Áládá Meji circula em torno do papel da religião para a comunidade e dos temas da violência sofrida pelos praticantes das religiões de matriz africana.

Para a entrevistada, a escola teria papel protagonista para a democratização do conhecimento e do respeito ao próximo, uma vez que a partir do ensino de histórias e mitologias africanas a criança passaria a conhecer mais sobre as sociedades africanas e não estranhariam os cos-

\begin{tabular}{|c|c|c|c|}
\hline Endereço do Terreiro & Nome do Terreiro & $\begin{array}{l}\text { Divindade } \\
\text { que rege }\end{array}$ & $\begin{array}{l}\text { Babalorixá ou } \\
\text { Zelador(a) }\end{array}$ \\
\hline Rua Paraibano, 43 & $\begin{array}{c}\text { Ilé Asé Ómòórisá Ógún } \\
\text { Áláádá Meji }\end{array}$ & Ógún & Vadinho de Ógùn \\
\hline Rua Santa Maria do Pará, 353 & ? & ? & Vó Catarina \\
\hline Rua Paulo Lopes & $?$ & $?$ & Analice \\
\hline Rua Jesuânia, 51 & $\begin{array}{l}\text { Ylê de Angoromeia } \\
\text { Viva Deus Neto }\end{array}$ & $?$ & Geralda \\
\hline Rua Baependi & $?$ & $?$ & $?$ \\
\hline Rua Conceição da Pedra & ? & ? & ? \\
\hline Rua São Gonçalo do Pará, 153 & ? & $?$ & Leda \\
\hline Rua 12 de junho, 80 & $\begin{array}{l}\text { Templo de Umbanda } \\
\text { Caboclo Sete Flechas e } \\
\text { Pai Joaquim de Angola }\end{array}$ & Preto Velho & $\begin{array}{l}\text { Antonio H. } \\
\text { Akiyoshi }\end{array}$ \\
\hline
\end{tabular}

Tabela 3: Relação de terreiros no Bairro de Bonsucesso indicados por crianças locais. 


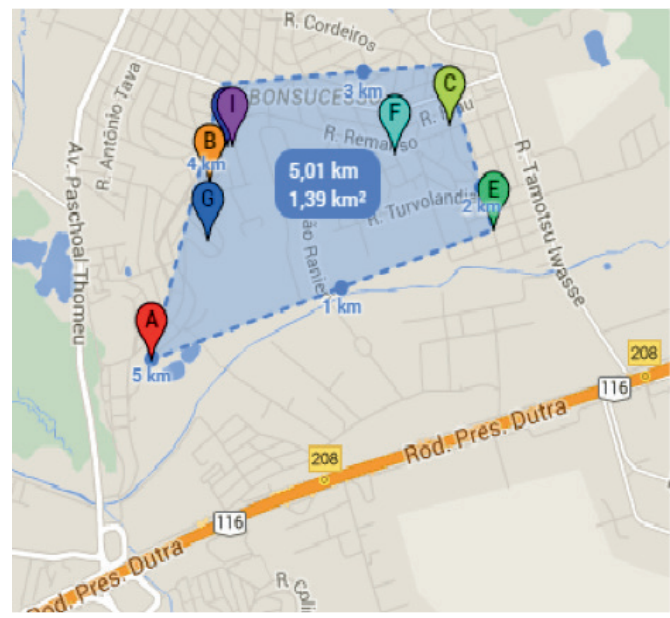

Fig. 1. Localização de terreiros no Bairro do Bonsucesso.

tumes e as práticas advindas desse continente.

Para Mãe Clarice é a ignorância sobre a cultura negra que leva à discriminação de praticantes da religião. Mesmo entre pessoas com alto nível de escolaridade, o não conhecimento da cultura negra acarreta problema. Como exemplo, ela relata um caso recente em que uma promotora, vizinha a um terreiro de candomblé em São Paulo, teria entrado no espaço de culto, quebrando e profanando o lugar, por conta do barulho.

Mãe Clarice ressalta a questão da antiguidade e continuidade histórica nas relações das comunidades negras, informando acerca da existência de antigos sítios arqueológicos indígenas e da cultura negra que durante a urbanização da cidade foram localizados. Mas Mãe Clarice informa que não se sabe sobre o destino do material arqueológico.

Ela aponta o terreiro da Mãe Dalva, terreiro de Candomblé de Angola localizada na favela do Jardim Cumbica, como um dos terreiros mais antigos ainda em prática, com mais de 30 anos de atividades. A explicação é que esse é o mais antigo ainda em atividade, pois o Ilê Orinxalá Fun Fun, tendo sofrido recente ordem de despejo, teve de paralisar as atividades no terreiro original e começar a realizar a prática em outro lugar. Nesse ponto, a entrevistada solicita o auxílio da UNIFESP com as questões patrimoniais desse terreiro, lembrando que o caso se encontra em debate sobre a pertinência de seu tombamento no Conselho do Patrimônio Histórico,
Artístico, Ambiental e Cultural do Município de Guarulhos.

Para a entrevistada, o papel de seu ilê axé é auxiliar a comunidade que a procura. Ela faz questão de dizer que, em contrapartida, também exige que a comunidade que a procura volte aos estudos, pois ela não acredita que as pessoas possam melhorar de vida por meio de solicitações aos santos se elas próprias não se esforçarem no dia a dia para conseguirem melhores empregos e, sucessivamente, melhor qualidade de vida.

Mãe Clarice ressalta as "Caminhadas das Águas de Oxum” promovida por eles, da União dos Adeptos das Religiões Afro-Brasileiras (Ua$\mathrm{rab}$ ), conjuntamente com a prefeitura municipal, no final da primeira semana de dezembro.

Ela diz que tem sido cada vez mais frequente a procura pela religião por indivíduos da classe média, embora em sua fala ainda seja citado o alto número de frequentadores com problemas sociais e de baixa escolaridade.

Uma das entrevistadoras, aluna da Unifesp, é conhecida de Mãe Clarice, o que permitiu, em alguns pontos da entrevista, que ambas trocassem ideias sobre problemas que ambas vivenciam nas comunidades quanto às religiões de matriz africana.

\section{Considerações Finais}

A migração para o trabalho em multinacionais durante o século XX levou a Guarulhos pessoas de diferentes religiões e diferentes condições sociais. A partir da década de 1950, o candomblé e depois a umbanda passam a ganhar cada vez mais adeptos e a abertura de terreiros em todo o município se multiplicou.

Os dados da FUCESP apontam para a importância dos terreiros no patrimônio religioso de Guarulhos, tendo mais terreiros per capita do que as demais cidades paulistas.

A princípio, o mapeamento verifica a existência de dois eixos importantes com concentração de terreiros, na área leste e oeste do município, que compreendem dois dos núcleos coloniais mais antigos. É nas adjacências de antigas rotas do período colonial onde são 
localizados frequentes cultos em meio a mata, próximo a fontes d'água.

Os terreiros se apresentam dispersos no município, porém muito próximos uns aos outros no que se refere a distância física, indicando uma rede interconectada nas relações sociais que se desdobra na utilização do espaço.

Talvez esses dois eixos indiquem a necessidade do contato com a natureza para a realização dos cultos, ou ainda que, a princípio, os praticantes das religiões tentaram se afastar da área central da cidade e, consequentemente, do olhar da sociedade. Se essa situação fazia sentido no começo, hoje o culto às religiões de matriz africana já é mais aceito pela sociedade e menos velado, embora ainda não seja de todo livre. Pois a violência, o bullying, o despejo e as ameaças ainda impactam a vida de seus praticantes, como relatado por Mãe Clarice e, como pudemos notar, pela falta de receptividade da comunidade para o mapeamento de seus terreiros.

A "Caminhadas das Águas de Oxum" é o momento em que a comunidade, junto com o poder público, tem exteriorizado publicamente seus problemas nos últimos anos, principalmente o da violência sofridos pelos praticantes das religiões de matriz africana.

A alta quantidade de terreiros e oferendas encontradas em Guarulhos são representativos de uma prática disseminada e arraigada nos costumes locais. Para uma sociedade recentemente forjada no trabalho de migrantes, os terreiros proporcionam alento às comunidades ao tratar de seus problemas e auxiliar em busca de soluções.

Desde o período da escravidão até os dias atuais, as comunidades negras sofrem violências físicas e psicológicas. No período da escravidão, o banzo, sentimento de apatia e tristeza, sofrimentos psíquicos decorrentes dos efeitos da discriminação racial e exclusão social, abatia-se sobre os escravos (Alves e Sminotti, 2009).

Continuamente, os problemas de sentimentos de inferioridade, insegurança e angústia não mais representam problemas isolados da cultura negra, mas perpassam por toda a população que, dentro da metrópole, não consegue atender às expectativas de um paradigma de vida bem-sucedida.

Nessa busca pela reorganização das vidas, a prática de religiões de matriz africana, sem preceitos moralistas de certo e errado, atendem qualquer indivíduo que procure ajuda. $\mathrm{O}$ candomblé, por exemplo, concebe o mundo como ele é e aceita comportamentos muitas vezes rejeitados por outras religiões, como, por exemplo, o sucesso, a dominação, o dinheiro, o poder e o prazer (Prandi, 1995: 81).

De acordo com Hubert (2011), as oferendas, vínculos entre as esferas humanas e divinas e de importância singular nos cultos de matriz africana, atuam como moeda de troca entre pessoas e divindades em busca de soluções para seus problemas. Trata-se, portanto, de um pagamento em caráter de reciprocidade ${ }^{1}$.

O alto número de oferendas localizadas em todo o município demonstra insatisfações pessoais e pedido de auxílio manifestados pela coletividade. Mas se os terreiros e as oferendas estão disseminados por toda a cidade, ocorre o oposto com sua cultura. Embora saibamos agora do elevado número de terreiros em Guarulhos, não sabemos sobre suas práticas, seus cantos, suas realizações socioculturais e suas aflições.

Candomblé e umbanda, as duas expressões religiosas de matriz africana de que tivemos notícias em Guarulhos, são ainda marginalizados e apartados no contexto social. Os frequentadores dos terreiros estão à margem das estatísticas oficiais e, do ponto de vista patrimonial, estão isolados, não encontrando abertura para a valorização de suas culturas.

Apesar da longa história de batalha contra a violência e a perseguição às religiões de matriz africana, a marginalização desta expressão cultural se mantém como em uma linha contínua, mas agora por meio da ignorância social de seu valor cultural que segrega essa cultura e a história de seus frequentadores.

Mas o sagrado tem seus métodos, as lendas se sabem defender. Mia Couto

- "Estórias abensonhadas" (2012).

1 Reciprocidade é um conceito da sociologia forjado por Marcel Mauss onde as relações sociais são símbolos com significados, que implicam em considerações recíprocas, expectativas e estratégias. Para saber mais, ver MAUSS, Marcel. "Ensaio sobre a Dádiva”. In: Sociologia e Antropologia. São Paulo: EPU, 1974. 
PLENS, C.R. African-Brazilian religions ritual areas in Guarulhos. R. Museu Arq. Etn., 26:151-162, 2016.

Abstract: Although the local African religions are barely known, some data reveal their importance in the city of Guarulhos when comparing with other cities in the State of São Paulo. This paper triggers a discussion about this importance by doing a first reading of the representativeness of religious ritual areas, Candomblé Temples, called "terreiros," in the city, and proposing further investigation of the matter in order to foster historical and cultural awareness. This awareness, when connected to religion, allows a better understanding of these religions by the public and the development of research and heritage preservation policies.

Keywords: Afro-Brazilian religions; Archaeology of Sacred Places; religious intolerance.

\section{Referências Bibliográficas}

Alves, M.C.; Sminotti, N. 2009. Atenção à saúde em uma comunidade tradicional de terreiro. Revista de Saúde Pública, v. 43 (1): 85-91.

Amaral, R.; Silva, V.G. 2006. Religiões Afro-brasileiras e Cultura Nacional: uma etnografia em hipermídia. Revista Pós-Ciências Sociais, v. 3, n. 6. São Luís.

Amado, J. 1964. Os Pastores da Noite. São Paulo: Martins.

Bowser, B.J.; Zedeño, M.N. 2009. The Archaeology of Meaningful Places. Salt Lake City: University of Utah Press.

Bradley, R. 2000. An Archaeology of Natural Places. London: Routledge.

Couto, M. 2012. Estórias Abensonhadas. São Paulo: Companhia das Letras.

Earle, T. 2009. Routes through the Landscape: A comparative Approach. In: Snead, J.E. et al. (Eds.) Landscapes of Movement. Trails, Paths, and Roads in Anthropological Perspective. University of Pennsylvania Museum of Archaeology and Anthropology: 253-269.
Erickson, C.L. 2009. Agency, Causeways, Canals, and the Landscapes of Everyday Life in the Bolivian Amazon. In: Snead, J.E. et al. (Eds.). Landscapes of Movement. Trails, Paths, and Roads in Anthropological Perspective, University of Pennsylvania Museum of Archaeology and Anthropology: 204-31.

Forbes, H. 2007 Meaning and Identity in a Greek Landscape: An Archaeological Ethnography. Cambridge: Cambridge University Press.

IBGE. http://cidades.ibge.gov.br/xtras/perfil. php?lang $=\& \operatorname{codmun}=351880 \&$ search $=$ sao -paulo | guarulhos

Hubert, J. 1994. Sacred Beliefs and Beliefs of Sacradness. In: Carmichael, D.L.; Hubert, J.; Reeves, R.; Schamel, A. (Eds.). Sacred Sites, Sacred Places. London: Routledge: 9-19.

Hubert, S. 2011. Manjar dos deuses: as oferendas nas religiões afro-brasileiras. Primeiros Estudos, São Paulo, v. 1: 81-104.

Orser, C.; Funari, P.P. 2001. Archaeology and slave resistence and rebellion. World Archaeology, 33: 61-72. 
Prandi, R. 1991. Os candomblés de São Paulo: A velha magia na metrópole nova. São Paulo: Hucitec e Edusp.

Prandi, R.; Pierucci, F. 1996. A realidade social das religiões no Brasil. São Paulo: Hucitec.

Prandi, R. 2004. O Brasil com axé: candomblé e umbanda no mercado religioso. Estudos Avançados, 18 (52): 223-38.

Prandi, R. 2009. Religião e sincretismo em Jorge Amado. In: Schawarcz, L.M.; Goldstein, I.S. (Orgs.). O universo de Jorge Amado. São Paulo: Companhia das Letras, v. 1: 46-61.

Santos, W.C.S. 2014. Preservação dos Ilês Axés: liberdade religiosa e tombamento de terreiros de candomblé da Bahia. III Encontro Internacional de Direitos Culturais. Outubro de 2014. Disponível em www.direitosculturais.com. br/download.php?id=218
Snead, J.E. 2009. Trails of Tradition: Moment, Meaning, and Place. In: Snead, J.E. et al. (Eds.). Landscapes of Movement. Trails, Paths, and Roads in Anthropological Perspective, University of Pennsylvania Museum of Archaeology and Anthropology: 42-60.

Snead, J.E.; Ericson, C.L.; Darling, A. Making human space: the archaeology of trails, paths and roads. In: Snead, J.E. et al. (Eds.). Landscapes of Movement. Trails, Paths, and Roads in Anthropological Perspective, University of Pennsylvania Museum of Archaeology and Anthropology: 1-19.

Velho, G. 2006. Patrimônio, negociação e conflito. Mana, Rio de Janeiro. v. 12 (1).

Site Consultado

Federação de Umbanda e Candomblé do Estado de São Paulo: http://www.fucesp.com/ filiados/, Acesso em: 23 nov. 2014 